\title{
RESEARCH
}

Open Access

\section{Estimating the potential for dementia prevention through modifiable risk factors elimination in the real-world setting: $a$ population-based study}

Elena Rolandi ${ }^{1}$, Daniele Zaccaria ${ }^{1,2}$, Roberta Vaccaro $^{1 *}$ D, Simona Abbondanza ${ }^{1}$, Laura Pettinato ${ }^{1}$, Annalisa Davin ${ }^{1}$ and Antonio Guaita ${ }^{1}$

\begin{abstract}
Background: Preventing dementia onset is one of the global public health priorities: around 35\% of dementia cases could be attributable to modifiable risk factors. These estimates relied on secondary data and did not consider the concurrent effect of non-modifiable factors and death.

Here, we aimed to estimate the potential reduction of dementia incidence due to modifiable risk factors elimination, controlling for non-modifiable risk factors and for the competing risk of death.

Methods: Participants from the InveCe.Ab population-based prospective cohort (Abbiategrasso, Italy) without a baseline dementia diagnosis and attending at least one follow-up visit were included $(N=1100)$. Participants underwent multidimensional assessment at baseline and after 2, 4, and 8 years, from November 2009 to January 2019. Modifiable risk factors were low education, obesity, hypertension, diabetes, depression, smoking, physical inactivity, hearing loss, loneliness, heart disease, stroke, head injury, and delirium. Non-modifiable risk factors were age, sex, and APOE $\varepsilon 4$ genotype. The primary endpoint was dementia diagnosis within the follow-up period (DSM-IV criteria). We performed competing risk regression models to obtain sub-hazard ratio (SHR) for each exposure, with death as competing risk. The exposures associated with dementia were included in a multivariable model to estimate their independent influence on dementia and the corresponding population attributable fraction (PAF).

Results: Within the study period (mean follow-up, 82.3 months), 111 participants developed dementia (10.1\%). In the multivariable model, APOE $\varepsilon 4(\mathrm{SHR}=1.89,95 \% \mathrm{Cl} 1.22-2.92, p=0.005)$, diabetes $(\mathrm{SHR}=1.56,95 \% \mathrm{Cl} 1.00-2.39, p=$ 0.043 ), heart disease (SHR $=1.56,95 \% \mathrm{Cl} 1.03-2.36, p=0.037)$, stroke (SHR $=2.31,95 \% \mathrm{Cl} 1.35-3.95, p=0.002)$, and delirium ( $\mathrm{SHR}=8.70,95 \% \mathrm{Cl} 3.26-23.24, p<0.001)$ were independently associated with increased dementia risk. In the present cohort, around $40 \%$ of dementia cases could be attributable to preventable comorbid diseases.

\footnotetext{
* Correspondence: r.vaccaro@golgicenci.it

1"Golgi Cenci" Foundation, Corso San Martino 10, 20081 Abbiategrasso, Italy

Full list of author information is available at the end of the article
}

(c) The Author(s). 2020 Open Access This article is licensed under a Creative Commons Attribution 4.0 International License, which permits use, sharing, adaptation, distribution and reproduction in any medium or format, as long as you give appropriate credit to the original author(s) and the source, provide a link to the Creative Commons licence, and indicate if changes were made. The images or other third party material in this article are included in the article's Creative Commons licence, unless indicated otherwise in a credit line to the material. If material is not included in the article's Creative Commons licence and your intended use is not permitted by statutory regulation or exceeds the permitted use, you will need to obtain permission directly from the copyright holder. To view a copy of this licence, visit http://creativecommons.org/licenses/by/4.0/ The Creative Commons Public Domain Dedication waiver (http://creativecommons.org/publicdomain/zero/1.0/) applies to the data made available in this article, unless otherwise stated in a credit line to the data. 
(Continued from previous page)
Conclusions: APOE $\varepsilon 4$, diabetes, heart disease, stroke, and delirium independently increased the risk of late-life
dementia, controlling for the competing risk of death. Preventive intervention addressed to these clinical populations
could be an effective approach to reduce dementia incidence. Further studies on different population-based cohort
are needed to obtain more generalizable findings of the potential of dementia prevention in the real-world setting.

Trial registration: ClinicalTrials.gov, NCT01345110.

Keywords: Dementia, Alzheimer's disease, Modifiable risk factors, Dementia prevention, Public health, Population attributable fraction, Aging

\section{Background}

Late-onset dementia is a multi-factorial disorder causing huge economic and social costs for public health and families. Advancing age remains one of the main risk factors for dementia: from 65 years, dementia prevalence nearly doubled every 5 years [1]. Thus, in absence of any effective treatment and considering the worldwide increase in life expectancy, the global prevalence of dementia is expected to constantly grow in the next decades [2]. In this view, preventing or delaying dementia onset is one of the global public health priorities. The Lancet International Commission on Dementia Prevention, Intervention and Care points out that around 35\% of dementia cases could be prevented targeting 9 modifiable risk factors in different life periods: low education in early life, hearing loss, hypertension and obesity in midlife, smoking, depression, physical inactivity, diabetes, and social isolation in late-life [3].

Beyond these cardiovascular and lifestyle factors, other preventable medical conditions increased dementia risk, such as stroke [4], delirium [5], heart disease [6], and traumatic brain injury [7].

Moreover, non-modifiable factors, such as age and APOE $\varepsilon 4$, significantly increase the risk of dementia and should be taken into account. Another important confounding which is rarely considered in disease outcome research is the concurrent risk of death, which is particularly relevant in older population and, if not considered, may lead to biased estimation of risk [8].

The InveCe.Ab study (Invecchiamento Cerebrale in Abbiategrasso, i.e., Brain aging in Abbiategrasso; ClinicalTrials.gov, NCT01345110) is a population-based study aimed to estimate dementia incidence and to explore socio-demographic, clinical, and lifestyle factors associated with aging and dementia [9]. The InveCe.Ab participants underwent multidimensional evaluations across 8 years, thus allowing both the collection of a wide range of risk factors at baseline and the prospective detection of dementia onset within the study period.

The present study aimed to estimate the potential reduction of dementia incidence due to modifiable risk factors elimination, taking into account the concurrent effect of non-modifiable risk factors and the competing risk of death. This approach would provide a more naturalistic picture of the potential of dementia prevention in the real-world setting, based on primary data from a population-based prospective cohort study and concurrently considering almost all the known risk factors.

\section{Methods}

\section{Participants}

The InveCe.Ab study is a single-step multidimensional population-based study, which comprised both a crosssectional and a longitudinal phase. The eligible population consisted of all the 1773 people born between 1935 and 1939 and residing in Abbiategrasso (Milan, Italy) on the prevalence day (November 1, 2009). This age range (7074 years) is considered a transitional age between late adulthood and old age in which persons usually notice the first cognitive changes leading to medical help seeking, but are still responsive to social, cardiovascular and lifestyle protective factors [9]. The study design is described in details elsewhere [9]. Briefly, 1321 older adults agreed to participate in the study and underwent a multidimensional assessment. Enrolled participants were re-contacted after 2, 4, and 8 years to perform follow-up evaluations, using the same assessment procedures of the baseline ones. Participants were eligible for the present investigation if they completed the baseline neuropsychological and medical assessments, confirming the absence of dementia, mental retardation, or psychosis, and attended at least one follow-up visit across 8 years.

All the participants provided written informed consent to the study procedures, which were in accordance with the Declaration of Helsinki. The study protocol was approved by the Ethics Committee of the University of Pavia on October 6, 2009 (Committee report 3/2009).

\section{Multidimensional assessment}

The multidimensional assessment consisted of blood sampling, social and lifestyle interview, geriatric visit, and neuropsychological assessment.

During the social and lifestyle interview, trained personnel help participants to compile self-report 
questionnaires on socio-demographics features and lifestyle habits.

The geriatricians collected a guided and detailed medical history, recorded current medications, and performed physical examination with special attention to neurologic signs and symptoms. Participants were further asked to bring medical reports of ambulatory visits and hospitalizations occurred in the period preceding the visit.

The neuropsychologists investigated the presence of the DSM-IV-TR (Diagnostic and Statistical Manual of Mental Disorders IV) criteria for major depression and dysthymia through clinical interview and administered the 15-items form of the Geriatric Depression Scale (GDS, [10]). A comprehensive neuropsychological test battery was administered to evaluate global cognition and the main cognitive domains (language, memory, attention, executive functions, visuo-spatial abilities).

All the details on instruments and study procedures are reported in the previously published study protocol [9].

\section{Risk factors: operational definitions}

The main established modifiable and non-modifiable risk factors for dementia were detected at each wave of the InveCe.Ab study. For the aim of the present investigation, baseline exposure to the risk factors was considered. Table 1 summarizes the operational definitions for each risk factor, which are further detailed in the present paragraph.

\section{Non-modifiable risk factors}

The DNA of each participant was extracted from blood sample and analyzed using real-time PCR (Applied Biosystems) to ascertain the presence of the APOE $\varepsilon 4$ genotype. As regards age, participants were stratified in two subgroups according to birth cohort (i.e., 1935-1937 versus 1938-1939). No conclusive evidence exists on the effect of sex on dementia incidence; however, several studies showed sex-specific susceptibility to risk factors and different disease manifestation in Alzheimer's disease [11]; therefore, we considered female sex as a nonmodifiable risk factor.

\section{Modifiable risk factors}

Low education was defined as less or equal than 5 years of formal education attendance, corresponding to primary school completion.

Body mass index (BMI) was calculated with the appropriate formula $\left(\mathrm{kg} / \mathrm{m}^{2}\right)$, and obesity was ascertained by a BMI greater or equal to 30 .

Hypertension was confirmed if at least one of the following conditions was present: (i) systolic blood pressure greater than $130 \mathrm{mmHg}$; (ii) diastolic blood pressure greater than $80 \mathrm{mmHg}$; and (iii) use of antihypertensive
Table 1 Summary of the operational definitions of the modifiable and non-modifiable risk factors

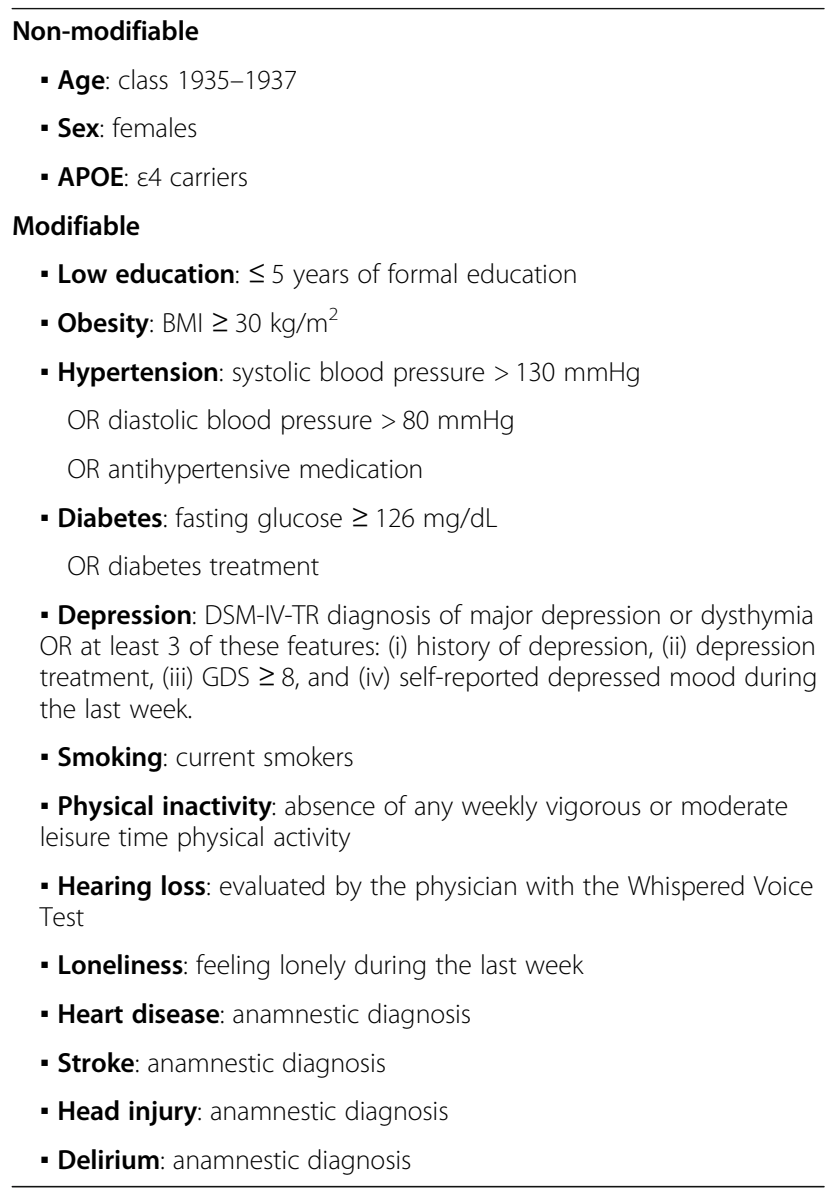

medications such as angiotensin-converting-enzyme inhibitor (ACE inhibitor), calcium antagonist, angiotensinII- receptor antagonists (sartans), diuretics, or beta blockers.

Diabetes was confirmed if at least one of the following conditions was present: (i) fasting glucose greater or equal to $126 \mathrm{mg} / \mathrm{dL}$ and (ii) use of insulin or oral hypoglycemic treatment.

Depression was evaluated combining information collected during the medical and neuropsychological assessment, as previously reported [12]. Briefly, clinically significant depression was established if DSM-IV-TR criteria for major depression or dysthymia were fulfilled [13] or if at least 3 of the following features were present: (i) history of depression; (ii) use of antidepressant or anxiolytic/hypnotic drugs; (iii) GDS $\geq 8$; and (iv) self-reported depressed mood during the last week.

Smoking and physical activity habits were investigated during the social and lifestyle interview. Current smoking was considered a risk condition. Physical inactivity was defined as the absence of any weekly leisure time physical activity. 
The physician clinically evaluated hearing ability with the Whispered Voice Test, in which the examiner stands behind the seated patient and whispers a standardized combination of six numbers and letters. Hearing loss was ascertained if participants repeated less than 3 items [14].

Self-perceived loneliness was investigated by the following yes/no single question asked by the physician: "Have you felt lonely/abandoned often during the last week?" $[15,16]$.

Finally, the physicians investigated the anamnestic diagnoses of heart disease (myocardial infarction, cardiac dysrhythmias, heart failure, angina pectoris, coronary bypass), stroke, head injury and delirium (medical history based on DSM-IV-TR criteria [13]).

\section{Outcome: dementia diagnosis}

The primary endpoint for the present study was cumulative incidence of all-cause dementia within the study period. At each evaluation wave, after medical and neuropsychological assessment completion, an expert geriatrician (A.G.) confirmed the presence/absence of dementia, based on the DSM IV-TR criteria for dementia syndrome. If the diagnosis was firstly formulated after the study visits, dementia onset was set at the date of the corresponding evaluation wave. Alternatively, if a dementia diagnosis was already made during the period between consecutive study visits, the date of the diagnosis formulation was retrospectively collected.

\section{Statistical analysis}

All the statistical analyses were done using Stata release 15 (StataCorp 2017). Firstly, using a Pearson's Chisquare test, we compared the proportion of nonmodifiable and modifiable risk factors exposure between participants who developed dementia over the follow-up period with those who did not. We considered statistically significant difference if $p$ value is equal or less than 0.050 . Then, assuming that death has to be considered an event that precludes the occurrence of our event of interest, that is diagnosis of dementia, we performed competing risk models, with death as a competitive event [17-19]. Considering the prediction nature of our main research aim, we fitted univariable Fine and Gray's semiparametric proportional sub-distribution hazards models to obtain sub-hazard ratios (SHRs), with $95 \% \mathrm{CI}$, representing the effect of each risk factor on the cumulative incidence function (CIF) of dementia and death in a competing risk situation [20-22]. We considered time in months from the baseline evaluation as a basic timescale variable, and date of first evaluation as the time origin. The risk factors found to have a significant sub-hazard ratio at level $p<0.150$ in univariable models regarding the event of interest (dementia) were included in the competing risks multivariable model, similarly to what has been done by Ritchie and colleagues [23]. The assumption of proportionality of hazards for both univariable and multivariable models were assessed testing statistical significance of interaction terms involving failure time. We used the default function of time $g(t)=t$ (see Additional file 1 for details).

Finally, we calculated the population attributable fraction (PAF) with $95 \%$ CI for each risk factor considered in the multivariable model, which estimates the proportion of incident cases in a given period that would be prevented if the exposure was entirely eliminated. It takes into account both the relative risk and the frequency of the risk factor in the population studied. In our case, PAF means proportion in risk reduction over 8 years that would be obtained if a specific exposure was entirely eliminated from the InveCe.Ab cohort, while the distribution of other risk factors included in the model remains unchanged. PAF is calculated subtracting population unattributable fraction (PUF), and its confidence limits, from 1. In this way, we compared a hypothetic scenario in which no one is exposed to the given risk factor and the world in which the data were collected. PAF is calculated using the "punafcc" command in Stata [24].

\section{Results}

Figure 1 displays the flowchart of case selection. At baseline, 1254 cases met the inclusion criteria. Among them, 154 participants did not complete any follow-up visit across 8 years, resulting in a sample for the present investigation of 1100 older adults without a baseline dementia diagnosis aged between 70 and 74 years. Within the study period, 111 participants developed dementia (10.1\%). The mean follow-up period was 82.3 months.

Table 2 reports the non-adjusted comparisons of baseline non-modifiable and modifiable risk factors exposure between participants who developed dementia over the follow-up period with those who did not, with chisquared test. We found statistically significant differences concerning APOE $\varepsilon 4$ and the presence of heart disease, stroke, or delirium.

Table 2 further reports the results of univariable competing risk models, to identify which of the exposures considered affect the cumulative incidence of dementia along the observation period. Sub-hazard ratios were reported both for the event of interest (dementia) and for the competing event (death). APOE $\varepsilon 4$, diabetes, heart disease, stroke, and delirium increase dementia incidence at $p<0.05$. Moreover, a trend toward significance was found for physical inactivity and low education $(p<0.150)$. As regards the competing event, depression, smoking, and stroke 


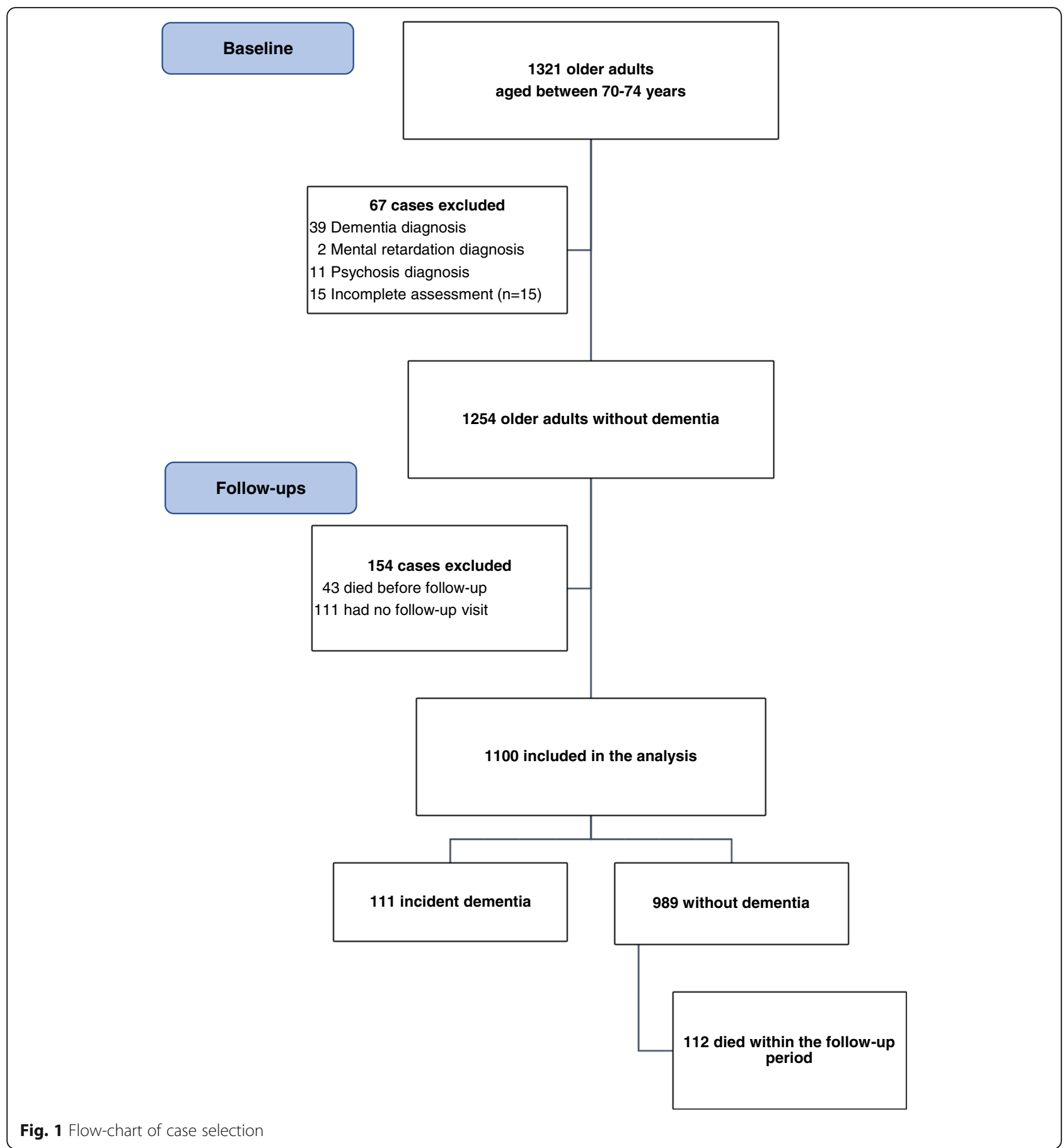

significantly increase the cumulative incidence of death within the observation period.

Then, we included all the exposures found to be significant for dementia incidence at level $p<0.150$ in the previous step, in a multivariable subdistribution hazards model with death as competing event (Table 3). We found that APOE $\varepsilon 4$, diabetes, heart disease, stroke, and delirium, independently considered, produce a significant increase in the cumulative incidence of dementia. With regard to the competing event, diabetes and stroke independently increase the cumulative incidence of death.

Finally, PAF estimations are reported, which showed the portion of dementia cases independently attributable to each modifiable risk factor, ranging from $5.7 \%$ for delirium to $13.6 \%$ for heart disease. 
Table 2 Descriptive variables and impact of each factor on dementia incidence across 8 years, based on univariable models, with death as a competing event

\begin{tabular}{|c|c|c|c|c|c|c|c|}
\hline \multirow[t]{2}{*}{ Risk factors } & \multirow{2}{*}{$\begin{array}{l}\text { Without dementia } \\
\mathbf{N}=989\end{array}$} & \multirow{2}{*}{$\begin{array}{l}\text { Incident dementia } \\
\mathbf{N}=111\end{array}$} & \multirow{2}{*}{$\begin{array}{l}\boldsymbol{X}^{2} \text { test } \\
\boldsymbol{P} \text { value }\end{array}$} & \multicolumn{2}{|c|}{ Death (competing event) } & \multicolumn{2}{|l|}{$\underline{\text { Dementia }}$} \\
\hline & & & & SHR $(95 \% \mathrm{Cl})$ & $\boldsymbol{P}$ value & SHR (95\% Cl) & $\boldsymbol{P}$ value \\
\hline \multicolumn{8}{|l|}{ Non-modifiable } \\
\hline Age (class 1935-37) & $522(52.7)$ & $69(62.2)$ & 0.060 & $1.21(0.82-1.78)$ & 0.332 & $1.20(0.82-1.78)$ & 0.347 \\
\hline Sex (female) & $534(54.0)$ & $55(49.5)$ & 0.373 & $0.76(0.53-1.11)$ & 0.156 & $0.82(0.56-1.19)$ & 0.287 \\
\hline APOE $\varepsilon 4$ & $166(16.8)$ & $34(30.6)$ & $<0.001$ & $0.92(0.47-12.16)$ & 0.742 & $2.00(1.34-3.01)$ & 0.001 \\
\hline \multicolumn{8}{|l|}{ Modifiable } \\
\hline Low education & $548(55.4)$ & $69(62.2)$ & 0.174 & $1.15(0.79-1.68)$ & 0.459 & $1.38(0.94-2.03)$ & 0.103 \\
\hline Obesity & $259(27.3)$ & $29(27.9)$ & 0.908 & $0.68(0.42-1.09)$ & 0.107 & $1.08(0.70-1.66)$ & 0.716 \\
\hline Hypertension & $685(69.4)$ & 81 (73.6) & 0.359 & $1.08(0.72-1.63)$ & 0.697 & $1.27(0.83-1.94)$ & 0.270 \\
\hline Diabetes & $198(20.2)$ & $31(28.2)$ & 0.053 & $1.30(0.84-12.96)$ & 0.200 & $1.55(1.02-2.36)$ & 0.042 \\
\hline Depression & $51(5.2)$ & $5(4.5)$ & 0.767 & $2.11(1.07-4.16)$ & 0.032 & $0.99(0.40-2.45)$ & 0.984 \\
\hline Smoking & $86(8.7)$ & $11(9.9)$ & 0.669 & $2.04(1.24-3.37)$ & 0.005 & $1.12(0.60-2.09)$ & 0.715 \\
\hline Physical inactivity & $462(46.8)$ & $60(54.1)$ & 0.145 & $1.27(0.88-1.84)$ & 0.203 & $1.42(0.98-2.06)$ & 0.064 \\
\hline Hearing loss & $123(12.5)$ & $16(14.5)$ & 0.539 & $1.07(0.62-1.83)$ & 0.803 & $1.20(0.71-2.02)$ & 0.493 \\
\hline Loneliness & 117 (11.9) & $10(9.1)$ & 0.388 & $1.31(0.77-2.21)$ & 0.316 & $0.82(0.42-1.59)$ & 0.562 \\
\hline Heart disease & $255(25.8)$ & $42(37.8)$ & 0.007 & $1.29(0.87-1.91)$ & 0.206 & $1.61(1.09-2.37)$ & 0.016 \\
\hline Stroke & $64(6.5)$ & $20(18.2)$ & $<0.001$ & $2.05(1.18-3.55)$ & 0.011 & $2.69(1.67-4.35)$ & $<0.001$ \\
\hline Head injury & $77(7.8)$ & $7(6.3)$ & 0.576 & $1.12(0.55-2.24)$ & 0.757 & $0.84(0.39-1.80)$ & 0.649 \\
\hline Delirium & $5(0.5)$ & $7(6.4)$ & $<0.001$ & $1.52(0.37-6.28)$ & 0.562 & $8.52(3.62-20.05)$ & $<0.001$ \\
\hline
\end{tabular}

Values represent counts (percentage)

SHR sub-hazard ratio

\section{Discussion}

In the present study, we aimed to evaluate the potential impact of dementia prevention through risk reduction in the real-world setting, using primary data from a population-based prospective cohort of older adults aged 70-74years and controlling for nonmodifiable factors and for the competing risk of death. Our findings expand and complement current knowledge on the potential impact of dementia prevention by including, beyond the nine modifiable risk factors acknowledged by the Lancet Commission, other preventable medical conditions associated with dementia, namely heart disease, stroke, head injury, and delirium. Among all the risk factors considered, APOE $\varepsilon 4$, diabetes, heart disease, stroke and delirium independently increased dementia incidence in late life. Overall, excluding the genetic risk that is not preventable, about $40 \%$ of dementia cases in the present population could be attributable to preventable comorbid diseases based on PAF estimations. Noteworthy, diabetes, stroke, heart disease, and delirium, which are also known to be associated with

Table 3 Independent influence of each risk factor on dementia incidence across 8 years, based on competing risk multivariable model

\begin{tabular}{|c|c|c|c|c|c|}
\hline \multirow[t]{2}{*}{ Risk factors } & \multicolumn{2}{|c|}{ Death (competing event) } & \multicolumn{2}{|l|}{ Dementia } & \multirow[b]{2}{*}{$\%$ PAF $(95 \%$ Cl) } \\
\hline & SHR (95\% Cl) & $\boldsymbol{P \text { value }}$ & SHR $(95 \% \mathrm{Cl})$ & $\overline{\boldsymbol{P} \text { value }}$ & \\
\hline APOE $\varepsilon 4$ & $0.93(0.57-1.51)$ & 0.761 & $1.89(1.22-2.92)$ & 0.005 & \\
\hline Low education & $1.18(0.80-1.73)$ & 0.803 & $1.42(0.95-2.11)$ & 0.087 & $18.5(1.3-23.4)$ \\
\hline Diabetes & $1.24(0.80-1.91)$ & 0.043 & $1.56(1.00-2.39)$ & 0.043 & $9.9(1.9-17.3)$ \\
\hline Physical inactivity & $1.22(0.84-1.78)$ & 0.297 & $1.33(0.90-1.96)$ & 0.152 & $13.3(3.9-27.7)$ \\
\hline Heart disease & $1.26(0.85-1.86)$ & 0.849 & $1.56(1.03-2.36)$ & 0.037 & $13.6(2.8-23.2)$ \\
\hline Stroke & $2.01(1.16-3.47)$ & 0.012 & $2.31(1.35-3.95)$ & 0.002 & $10(5.8-14.0)$ \\
\hline Delirium & $1.50(0.34-6.51)$ & 0.590 & $8.70(3.26-23.24)$ & $<0.001$ & $5.7(5.0-6.5)$ \\
\hline
\end{tabular}

SHR sub-hazard ratio, PAF population attributable fraction 
increased mortality [25-27], showed a significant and independent influence on dementia onset, even if death occurrence was controlled. These findings highlight the importance to address preventive initiative to these frail populations, already facing complex clinical needs. In terms of public health, focused and personalized preventive interventions embedded in the care pathways of these clinical populations could be an effective approach to reduce late-life dementia incidence. Another feasible and complementary approach is to further boost recommendations on cardiovascular health starting from middle age, as a common factor reliably related to several chronic diseases, leading to adverse outcomes and huge burden for families and communities, such as diabetes, stroke, heart disease, and dementia itself. The finding of delirium impact on dementia incidence deserves a separate dissertation. In our cohort, despite the small statistical power due to the few delirium cases detected, history of a delirium episode increased the likelihood of dementia incidence by 8 -fold. Moreover, the true impact of delirium in terms of PAF could be underestimated, since our variable is based on participants self-report. Indeed, it is known that delirium is frequently under-recognized in clinical practice [28], with low agreement on diagnosis even among delirium experts [29]. The tight and bidirectional relationship between delirium and dementia is widely reported, while the pathophysiological mechanism underlying this interplay is still poorly understood [5]. However, several preventive interventions are recommended to reduce the risk of delirium in hospitalized older adults, which should be easily implemented in clinical practice [30].

Regarding the other modifiable factors, trends toward significance were found for low education and physical inactivity. However, when all the relevant factors were concurrently tested, the impact of physical inactivity on dementia was reduced. This could be due to the co-presence of other factors in the multivariable model related to cardiovascular health, with possible overlapping effect.

Indeed, low levels of physical activity are an established risk factor for cardiac diseases and diabetes [31], both included in our multivariable model and exerting a significant effect on dementia incidence. It is therefore possible that physical activity act on dementia incidence through an indirect pathway (i.e., preserving cardiovascular health). However, even small amount of physical activity lead to measurable health benefits with low risk of harm and minimal cost [31-33]. Altogether, these findings support to include recommendations on the importance of physical activity for public health, even if the results on the direct effect on cognitive outcomes are not conclusive [33].
No associations were found between late-life hypertension or obesity and dementia, in line with previous evidences consistently showing a significant association with dementia only when these factors are detected in midlife [2, 3, 34, 35]. A counterintuitive finding is the lack of association between age and dementia. This could be due to the specific features of our study, which included by design individuals in a single age quintile at baseline (70-74 years), in order to minimize the confounding effect of age [9].

The discrepancies with previous findings could be also due to the different methodological approach used in the present study. Indeed, previous PAF estimates were calculated on secondary data from studies with heterogeneous designs (meta-analyses, observational, randomized controlled trial), and the co-occurrence of factors was indirectly controlled using communality of factors (i.e., the variance in observed variables accounted for by common factors) calculated on data from national repositories [2, 3, 36]. Conversely, we statistically tested the prospective associations of exposures with disease occurrence on primary data, including all the relevant exposures in the same model. Moreover, we further controlled for non-modifiable factors and for death occurrence within the study period. This led to a more conservative but more realistic estimation of the potential of dementia prevention through risk modification.

To the best of our knowledge, only one previous study investigated all the major modifiable and non-modifiable risk factors on a prospective cohort using a similar methodological approach. It showed an independent impact of APOE $\varepsilon 4$, diabetes, depression, low fruit/vegetable consumption, and cognitive reserve (i.e., crystallized intelligence) on dementia or mild cognitive impairment incidence, approaching an overall PAF of $40 \%$ for modifiable factors [37]. Therefore, even in a different cohort and measuring a different outcome, APOE $\varepsilon 4$ and diabetes were reliably associated with cognitive decline in late life.

The main strength of the present study is the methodological approach, which allows the statistical estimation of the potential of dementia prevention in the realworld setting, concurrently considering all the major modifiable and non-modifiable risk factors within the same population-based cohort. Population-based study controls for selection bias, being therefore particularly appropriate to investigate the potential of prevention through public health interventions addressed to the general population. Moreover, in our study, dementia diagnosis was set after multidimensional assessment and prospectively detected during the follow-up period, fulfilling the temporality criteria between the exposures and the outcome [38].

The main limitation of the study is the relatively low number of dementia cases, leading to reduced statistical power for the less prevalent risk factors. Moreover, since PAF is 
affected by the frequency of the risk factor in the population of interest, the generalizability of our results is limited to populations with the same key features of the InveCe.Ab cohort. Finally, the operationalization of some risk factors in the present study was not optimal, potentially reducing the sensitivity to detect the risk condition in a portion of cases. For example, hearing loss was evaluated by the clinicians instead of audiometry, loneliness was measured by a single yes/no question, and history of delirium was based on selfreport.

\section{Conclusions}

Our results show an independent influence of APOE $\varepsilon 4$, diabetes, heart disease, stroke, and delirium on dementia incidence across 8 years in older adults aged between 70 and 74 years. Focused and personalized preventive intervention addressed to these clinical populations and embedded in clinical practice could be an effective approach potentially leading to a $40 \%$ reduction in latelife dementia onset, controlling for death within the observation period and for the influence of non-modifiable factors. Further studies on the potential for dementia prevention in diverse populations are needed, since globally the number of dementia cases are expected to exponentially increase particularly in low- and middleincome countries [39].

\section{Supplementary information}

Supplementary information accompanies this paper at https://doi.org/10 1186/s13195-020-00661-y.

Additional file 1. Proportional sub-distribution hazards assessment for diagnosis of dementia. Description of data: assumption of proportionality of hazards for both univariable and multivariable models.

\section{Abbreviations}

BMI: Body mass index; DSM IV-TR: Diagnostic and Statistical Manual of Mental Disorders IV; GDS: Geriatric Depression Scale; PAF: Population attributable fraction; SHR: Sub-hazard ratios

\section{Acknowledgements}

The authors are grateful to "Federazione Alzheimer Italia," Milan, for supporting the "Golgi Cenci" Foundation's research activities. The authors thank Cariplo Foundation (Italy) for funding the third follow-up wave of the InveCe.Ab study in the frame of FrailBioTrack Project (FrailBioTrack 2017-0557).

\section{Authors' contributions}

ER conceived and designed the present study, interpreted the data, and drafted the manuscript; DZ conceived and performed statistical analyses, drafted the statistical analyses and results sections, and revised the manuscript; RV conceived and coordinated the collection of behavioral data and revised the manuscript for important intellectual content; SA, LP, and AD acquired data and revised the manuscript for important intellectual content; AG is the principal investigator of the InveCe.Ab study and revised the manuscript for important intellectual content. All the authors read and approved the final manuscript.

\section{Funding}

No funding was obtained for this study.

\section{Availability of data and materials}

The datasets used and analyzed during the current study are available from the corresponding author on reasonable request.

\section{Ethics approval and consent to participate}

The study was performed in accordance with the guidelines of the Declaration of Helsinki. The study was approved by the Ethics Committee of the University of Pavia on October 6, 2009 (Committee report 3/2009). All the participants provided written informed consent.

\section{Consent for publication}

Not applicable.

\section{Competing interests}

The authors declare that they have no competing interests.

\section{Author details}

1"Golgi Cenci" Foundation, Corso San Martino 10, 20081 Abbiategrasso, Italy. ${ }^{2}$ Department of Business Economics, Health and Social Care Centre of Competence on Ageing, University of Applied Sciences and Arts of Southern Switzerland, Stabile Piazzetta, Via Violino 11, CH-6928 Manno, Switzerland.

Received: 8 April 2020 Accepted: 28 July 2020

Published online: 07 August 2020

\section{References}

1. Lobo A, Launer LJ, Fratiglioni L, Andersen K, Di Carlo A, Breteler MM, et al. Prevalence of dementia and major subtypes in Europe: a collaborative study of population-based cohorts. Neurologic Diseases in the Elderly Research Group. Neurology. 2000;54:S4-9 Available from: http://www.ncbi.nlm.nih. gov/pubmed/10854354

2. Norton S, Matthews FE, Barnes DE, Yaffe K, Brayne C. Potential for primary prevention of Alzheimer's disease: an analysis of population-based data. Lancet Neurol. 2014;13:788-94 Available from: http://linkinghub.elsevier. com/retrieve/pii/S147444221470136X

3. Livingston G, Sommerlad A, Orgeta V, Costafreda SG, Huntley J, Ames D, et al. Dementia prevention, intervention, and care. Lancet. 2017;390:2673-734.

4. Ivan CS, Seshadri S, Beiser A, Au R, Kase CS, Kelly-Hayes M, et al. Dementia after stroke: the Framingham Study. Stroke. 2004;35:1264-8. Available from: https://www.ahajournals.org/doi/10.1161/01.STR.0000127810.92616.78.

5. Fong TG, Davis D, Growdon ME, Albuquerque A, Inouye SK. The interface between delirium and dementia in elderly adults. Lancet Neurol. 2015;14: 823-32 Available from: http://www.ncbi.nlm.nih.gov/pubmed/26139023.

6. Rusanen M, Kivipelto M, Levälahti E, Laatikainen T, Tuomilehto J, Soininen $H_{\text {, }}$ et al. Heart diseases and long-term risk of dementia and Alzheimer's disease: a population-based CAIDE study. J Alzheimer's Dis. 2014;42:183-91.

7. Fann JR, Ribe AR, Pedersen HS, Fenger-Grøn M, Christensen J, Benros ME, et al. Long-term risk of dementia among people with traumatic brain injury in Denmark: a population-based observational cohort study. Lancet Psychiatry. 2018:5:424-31. Available from: http://www.ncbi.n/m.nih.gov/ pubmed/29653873

8. Berry SD, Ngo L, Samelson EJ, Kiel DP. Competing risk of death: an important consideration in studies of older adults. J Am Geriatr Soc. 2010; 58:783-7

9. Guaita A, Colombo M, Vaccaro R, Fossi S, Vitali SF, Forloni G, et al. Brain aging and dementia during the transition from late adulthood to old age: design and methodology of the "Invece.Ab" population-based study. BMC Geriatr. 2013;13:98 Available from: BMC Geriatrics.

10. Wancata J, Alexandrowicz R, Marquart B, Weiss M, Friedrich F. The criterion validity of the geriatric depression scale: a systematic review. Acta Psychiatr Scand. 2006;114:398-410.

11. Ferretti M, lulita M, Cavedo E, Chiesa P, Schumacher Dimech A, Santuccione $A$, et al. Sex differences in Alzheimer disease - the gateway to precision medicine. Nat Rev Neurol. 2018. https://doi.org/10.1038/s41582-018-0032-9.

12. Vaccaro R, Borrelli P, Abbondanza S, Davin A, Polito L, Colombo M, et al. Subthreshold depression and clinically significant depression in an Italian population of 70-74-year-olds: prevalence and association with perceptions of self. Biomed Res Int. 2017:2017:1-8 Available from: http://www.ncbi.nlm. nih.gov/pubmed/28393076.

13. Diagnostic and Statistical Manual of Mental Disorders, Fourth Edition, Text Revision (DSM-IV-TR). 2000 
14. Vaccaro R, Zaccaria D, Colombo M, Abbondanza S, Guaita A. Adverse effect of self-reported hearing disability in elderly Italians: results from the InveCe. Ab study. Maturitas. 2019;121:35-40. https://doi.org/10.1016/j.maturitas.2018. 12.009 .

15. Jylhä M. Old age and loneliness: cross-sectional and longitudinal analyses in the Tampere longitudinal study on aging. Can J Aging. 2004;23:157-68.

16. Victor CR, Scambler SJ, Bowling A, Bond J. The prevalence of, and risk factors for, loneliness in later life: a survey of older people in Great Britain. Ageing Soc. 2005:25:357-75.

17. Dignam JJ, Zhang Q, Kocherginsky M. The use and interpretation of competing risks regression models. Clin Cancer Res. 2012;18:2301-8.

18. Noordzij M, Leffondré K, Van Stralen KJ, Zoccali C, Dekker FW, Jager KJ. When do we need competing risks methods for survival analysis in nephrology? Nephrol Dial Transplant. 2013;28:2670-7.

19. Schuster NA, Hoogendijk EO, Kok AAL, Twisk JWR, Heymans MW. Ignoring competing events in the analysis of survival data may lead to biased results: a nonmathematical illustration of competing risk analysis. J Clin Epidemiol. 2020;122:42-8. https://doi.org/10.1016/j.jclinepi.2020.03.004.

20. Fine JP, Gray RJ. A proportional hazards model for the subdistribution of a competing risk. J Am Stat Assoc. 1999;94:496-509.

21. Wolbers M, Koller MT, Witteman JCM, Steyerberg EW. Prognostic models with competing risks methods and application to coronary risk prediction. Epidemiology. 2009;20:555-61.

22. Austin PC, Lee DS, Fine JP. Introduction to the analysis of survival data in the presence of competing risks. Circulation. 2016;133:601-9.

23. Ritchie CW, Terrera G, Quinn TJ. Dementia trials and dementia tribulations: methodological and analytical challenges in dementia research. Alzheimers Res Ther. 2015;7:31 Available from: http://alzres.com/content/7/1/31.

24. Newson RB. Attributable and unattributable risks and fractions and other scenario comparisons. Stata J. 2013;13:672-98.

25. Witlox J, Eurelings LSM, De Jonghe JFM, Kalisvaart KJ, Eikelenboom P, Van Gool WA. Delirium in elderly patients and the risk of postdischarge mortality, institutionalization, and dementia: a meta-analysis. JAMA. 2010; 304:443-51.

26. Roglic G, Unwin N, Bennett PH, Mathers C, Tuomilehto J, Nag S, et al. The burden of mortality attributable to diabetes: realistic estimates for the year 2000. Diabetes Care. 2005;28:2130-5.

27. Murray CJL, Lopez AD. Mortality by cause for eight regions of the world: Global Burden of Disease Study. Lancet. 1997;349:1269-76.

28. Mossello E, Tesi F, Di Santo SG, Mazzone A, Torrini M, Cherubini A, et al. Recognition of delirium features in clinical practice: data from the "Delirium Day 2015" National Survey. J Am Geriatr Soc. 2018;66:302-8.

29. Numan T, van den Boogaard M, Kamper AM, Rood PJT, Peelen LM, Slooter AJC. Recognition of delirium in postoperative elderly patients: a multicenter study. J Am Geriatr Soc. 2017;65:1932-8.

30. Young J, Murthy L, Westby M, Akunne A, O'Mahony R. Guidelines. Diagnosis, prevention, and management of delirium: summary of NICE guidance. BMJ. 2010;341:247-8.

31. Wahid A, Manek N, Nichols M, Kelly P, Foster C, Webster P, et al. Quantifying the association between physical activity and cardiovascular disease and diabetes: a systematic review and meta-analysis. J Am Heart Assoc. 2016;5: e002495.

32. Eijsvogels TMH, George KP, Thompson PD. Cardiovascular benefits and risks across the physical activity continuum. Curr Opin Cardiol. 2016;31:566-71.

33. National Academies of Sciences, Engineering and M. Preventing cognitive decline and dementia: a way forward. Washington, DC: The National Academies Press; 2017

34. Walker KA, Power MC, Gottesman RF. Defining the relationship between hypertension, cognitive decline, and dementia: a review. Curr. Hypertens. Rep. Current Medicine Group LLC 1; 2017;19:24.

35. Baumgart M, Snyder HM, Carrillo MC, Fazio S, Kim H, Johns H. Summary of the evidence on modifiable risk factors for cognitive decline and dementia: a population-based perspective. Alzheimers Dement. 2015;11:1-9 Available from: http://www.ncbi.nlm.nih.gov/pubmed/26045020.

36. Mayer F, Di Pucchio A, Lacorte E, Bacigalupo I, Marzolini F, Ferrante G, et al. An estimate of attributable cases of Alzheimer disease and vascular dementia due to modifiable risk factors: the impact of primary prevention in Europe and in Italy. Dement Geriatr Cogn Dis Extra. 2018;8:60-71.

37. Ritchie K, Carrière I, Ritchie CW, Berr C, Artero S, Ancelin ML. Designing prevention programmes to reduce incidence of dementia: prospective cohort study of modifiable risk factors. BMJ. 2010;341:336.
38. Hill AB. The environment and disease: association or causation? J R Soc Med. 1965;

39. Prince M, Wimo A, Guerchet M, Gemma-Claire A, Wu Y-T, Prina M. World Alzheimer Report 2015: The Global Impact of Dementia - an analysis of prevalence, incidence, cost and trends; 2015. p. 84.

\section{Publisher's Note}

Springer Nature remains neutral with regard to jurisdictional claims in published maps and institutional affiliations.
Ready to submit your research? Choose BMC and benefit from:

- fast, convenient online submission

- thorough peer review by experienced researchers in your field

- rapid publication on acceptance

- support for research data, including large and complex data types

- gold Open Access which fosters wider collaboration and increased citations

- maximum visibility for your research: over $100 \mathrm{M}$ website views per year

At BMC, research is always in progress.

Learn more biomedcentral.com/submissions 